\title{
Comments on "The Ketamine Model of the Near-Death Experience: $A$ Central Role for the N-Methyl-D-Aspartate Receptor"
}

\author{
Antonio Bianchi, M.D. \\ General Hospital of Bergamo, Italy
}

ABSTRACT. Although ketamine can induce a state similar to a near-death experience (NDE), there is a striking difference between experiences induced by ketamine used in a recreational context and in an operating room. Ketamine is a noncompetitive antagonist of the N-methyl-D-aspartate receptor, as is ibogaine, the main alkaloid of a shrub used in Central Africa to induce NDEs in a religious context. Ibogaine can also elicit different experiences when used in a hallucinatory context or in initiatic rituals, where a superficial state of coma is induced. These data raise the question of whether the chemically-induced NDE-like experience is related to the use of a particular kind of substance or to a genuine comatose state.

The hypothesis devised by Karl Jansen on the role of N-methylD-aspartate (NMDA) receptors in near-death experiences (NDEs) is fascinating and very attractive, especially for those who, like myself, have always worked on the neurochemical and neurophysiological aspects of altered states of consciousness (ASCs). But this hypothesis is particularly fascinating because the identification of NMDA receptors as an essential neurochemical target in the development of an NDE allows interesting convergences with other neurophysiological models to be established, such as those of Daniel Carr (1982) and Juan Saavedra-Aguilar and Juan Gómez-Jeria (1989), and for the

Antonio Bianchi, M.D., is an anesthesiologist and toxicologist at the General Hospital of Bergamo in Italy. Reprint requests should be addressed to Dr. Bianchi at via Sommariva 5, 37131 Verona, Italy. 
first time allows a sort of "global vision" of the neurophysiology of NDEs.

Jansen, after having defined the hypothesis that the NMDA receptors are involved in the genesis of an NDE, rightly focused his attention on the possibility of provoking this type of experience through a chemical manipulation of the NMDA receptors. The most interesting chemical substance in this regard appears to be ketamine. It is true that NDEs have been associated with a great number of hallucinogens, including hashish (Siegel and Hirschman, 1984) and lysergic acid diethylamide (LSD) (Grof, 1994), but ketamine, an anesthetic still routinely used in surgery, has especially been associated with a high rate of NDEs (Rogo, 1984).

Ketamine was first synthesized in 1963, the first laboratory data date back to 1965 (McCarthy, Chen, Kaump, and Ensor, 1965), while the first pharmacological data on humans were published by Edward Domino and associates (Domino, Chodoff, and Corssen, 1965). It was Domino's team who coined the term "dissociative anesthesia" to denote the particular state provoked by the injection of 1 to 2 milligrams (mg) intravenously or of 3 to $5 \mathrm{mg}$ intramuscularly in patients; to describe this state they used the term "trance-like". However, it was immediately clear that the use of this drug was associated with a high number of "postanesthetic emergence reactions," the term used for an extremely varied range of psychological reactions, ranging from panic attacks to hallucinatory states, from temporal and spatial disorientation to genuine psychotic reactions. These states, especially when ketamine was used alone, affected 13.3 percent of patients (Parke-Davis and Co., 1969) and were soon interpreted as an organic cerebral toxicosis (Henry and Mann, 1965), though in the scientific literature their definition has been rather vague and they have been given other labels such as "sensory deprivation," "hallucinations," "pseudohallucinations," and "delirium" (Sedman, 1966).

This confusion in terminology has at times led to classifying ketamine among the hallucinogens, even if its psychophysiological effects are very different from the molecules usually defined as such. For example, comparing LSD with ketamine, it can be noted that the former induces a decrease in voltage of the electroencephalogram (EEG); there is an acceleration of activity; it does not produce anesthesia; it inhibits food intake; and it always causes phenomena of tolerance and a state of abstract hallucinations independent of reality with a strong perceptive component. Ketamine, on the other hand, induces a state characterized by an increase in EEG voltage, a slow- 
ing down of activity, and a deep anesthesia; it stimulates the appetite centers; it often provokes a retrograde amnesia; it never induces phenomena of tolerance; and the type of psychological effects induced largely depends on the environmental stimuli, with a marked action on proprioceptive perception of the individual's body. The psychological effects, and also the neurochemical target-serotonin receptors in the case of LSD and NMDA receptors in the case of ketamineappear to be completely different.

However, the classification of ketamine as a hallucinogen led, in the past, to its being used illegally both by means of intramuscular injections in doses of 1 to $2 \mathrm{mg}$ and taken orally in doses 8 to 10 $\mathrm{mg}$, by young people, seeking the psychedelic effects, considered undesirable in anesthesiological routine (Jansen, 1993; Johnstone, 1973). The frequency of anxiety or negative reactions led to the notion that the substance induced "bad trips" too often, and thus its use gradually became limited to highly restricted circles, to the extent that to date there is only one documented case of psychological dependence on this substance (Hurt and Ritchie, 1994). The material available today in the underground literature on this substance contains some useful information for the purposes of our analysis, corroborated by a number of my own attempts to induce an NDE through an intramuscular injection of ketamine.

It in fact appears that the recreational use of this substance may induce some components of an NDE, in particular the tunnel experience, the sense of hovering above one's own body, and the vision of a bright light (Moore and Alltounian, 1978), but these effects nevertheless seem to remain confined to the level of the intrapsychic world of the experiencer and are consequently experienced as "visions" or "hallucinations," lacking that sense of reality that is typical of the NDE. Furthermore, they are deprived of the strong emotional component that makes an NDE so important in the life of the individual experiencing it. This sense of reality and emotional involvement are, on the other hand, present in some subjects who have experienced the effects of ketamine during anesthesia (Collier, 1972), which is in fact a state of pharmacologically piloted coma, raising three interesting interpretative hypotheses.

First, the action of ketamine on NMDA receptors presents interesting analogies with what occurs during an NDE, which, given its complexity, nevertheless remains a distinct phenomenon with respect to the simple pharmacological action of this anaesthetic. Second, ketamine is capable of inducing a common experience that, when 
there is real danger to life, is experienced as an NDE, and otherwise as a simple "hallucination." Third, ketamine may induce a threshold experience that takes the subject close to a real NDE; the context in which it takes place is decisive in deciding whether it will trigger an NDE or not.

Whichever interpretation we incline toward, the importance of NMDA receptors cannot easily be set aside, especially in relation to the use of another substance: ibogaine. Ibogaine, the most important alkaloid of the plant Tabernanthe iboga, an Apocinacea of Central Africa, was isolated in the 1950s by French and Swiss chemists (Goutarel, Gollhofer, and Sillans, 1993). Renewed interest has recently been shown in ibogaine, especially in relation to its anti-addiction activity with regard to heroin, cocaine, amphetamines, nicotine, and alcohol (Lotsof and Sisko, 1991). Due to this unique pharmacological activity, ibogaine has been actively investigated in recent years and today we know that it acts on the dopaminergic system (Glick, Rossman, Dong, and Keller, 1993), on the serotonergic system (Sershen, Hashim, and Lajtha, 1994), on the mu-opioid receptors (Deecher, Teitler, Soderlund, Bornmann, Kuehne, and Glick, 1992), and on NMDA receptors (Popik, Layer, and Skolnick, 1994). This last action has been shown in a recent review (Popik, Layer, and Skolnick, 1995) to be one of the most important for the purposes of its anti-addiction activity, which furthermore appears closely connected with the psychological, and therefore psychotherapeutic, effects of the substance (Sheppard, 1994).

This leads us to consider the traditional use of the plant in Central Africa, where it has been used for centuries by the Pigmy, Bakota, and Bakwele tribes of the Congo, southern Cameroon, and eastern Gabon in a series of initiatory rites aimed at giving the members of the tribe a vision of the meaning of life and death in the passage from adolescence to adulthood. Subsequently the use of the plant spread to the Fang populations who, in more recent times, invaded Gabon from the north, where its use has given rise to a remarkable syncretist cult, rich in Catholic elements, known as Bwiti, considered today as the main religious form of this ethnic group. As I was able to observe during a recent trip, the use of iboga in the initiatory rites of the Bakota, the Bakwele, and the Pigmy is today strongly on the decrease, due to the rapid processes of acculturation of these tribes and the spread of new cults of possession from the East, while it maintains all its vitality within the Fang culture, in a highly culturally contaminated and acculturated context. 
The experience induced in Africa by taking strong doses of Tabernanthe iboga, doses capable of inducing a state of superficial coma, could be classified as an NDE without any difficulty: amongst the tribes of eastern Gabon it is interpreted as meeting the ancestors, whether men or animals; while among the Fang ethnic groups it is frankly defined as "meeting God." Personally, I have been present only at a ceremony of the Bakota, in the Makoukou district in the far east of the Gabon forest, where three girls volunteered to take part. The bark of Tabernanthe iboga root was administered to them for a period of more than two days, until on the second night two of them fell into a state of coma of a superficial type, as all their physiological parameters were normal. On awakening, they described an experience that may be summarized as follows:

(a) separation of the spirit from the physical body and gradual upwards ascension;

(b) overcoming a series of obstacles such as rivers and fire, or temptations such as banquets where meat, which subsequently turned out to be human flesh, was plentiful;

(c) encounters with dead relatives who gave each young girl advice on her future life; and

(d) for both girls, the experience came to a climax with an encounter with a leopard glowing with a shining, golden light, considered the totem animal of the whole Bakota ethnic group, which gives young girls the magic power that ensures that they will have many children, or in some cases the power to heal.

The day following this experience each young girl's behavior was trance-like, being possessed repeatedly by the spirit of the leopard. This component of possession appears to a somewhat lesser extent in the Fang ceremonies but raises interesting analogies between this type of experience and the physiology of states of possession, at times due to an activation of the right temporal limbic system (Peters and Prince-Williams, 1983).

This experience seems very similar to that reported by several anthropologists who have studied the Bwiti rites among the Fang. James Fernandez (1982), for example, in his monumental work on the Bwiti of the north of Gabon, reported numerous visions by the initiates, of which he highlighted a number of common elements:

(a) the separation of the spirit from the physical body;

(b) contact with the dead, often relatives of the initiate; 
(c) journeys in afterlife worlds and landscapes, within which there are often obstacles to be overcome;

(d) the climax of the experience is the contact with a bright power of divine nature, a concept that is in contrast absent from more ancient aboriginal contexts.

Stanislaw Swidersky (1990), who has, on the other hand, worked primarily with the Bwiti of the estuary where the signs of Christian acculturation are strongest, confirmed the general pattern, although in this case contacts with "spiritual guides," taken from Catholic iconography, become predominant and the natural landscapes of the forest are often replaced by journeys in "cities of light" located in afterlife worlds.

Of course, beyond the contents, which may vary due to cultural background, the initiatory experiences induced by iboga, while they stress the importance that substances acting on NMDA receptors may have, cannot be regarded as evidence in favor of an organic hypothesis of the NDE. The African initiation ceremonies involve the use of large quantities of the substance, which provoke, as mentioned above, a real, if superficial, state of coma; and, although rarely, this state may become irreversible for the neophyte, ending in death (Fernandez, 1982; Swidersky, 1990). Furthermore, once initiated, the initiate will take iboga periodically, but never again in such concentrated amounts, resulting in experiences that may easily be defined as "hallucinatory" but are very different from the initiatory journey, which, for many aspects, recalls the difference between the experiences induced by recreational doses and anesthetic doses of ketamine.

In conclusion, the similarity between ibogaine and ketamine, both of which are substances acting on NMDA receptors, and their capacity to provoke an NDE at certain doses and in an appropriate context, underlines the importance of NMDA receptors in the complex physiological picture that probably accompanies an NDE, even if it leaves the interpretative hypotheses that we had previously formulated without an answer. Are they chemical substances effectively capable of provoking an experience that is the same as an NDE? Or rather, do they provoke experiences similar to an NDE but distinguished by a number of fundamental characteristics, related or not to a real danger to life? Or do these substances perhaps activate some neurochemical mechanisms that lead the subject to a sort of threshold experience, which may be experienced as a simple hallucination if it 
is experienced recreationally or evolve towards a real NDE if there is a real physiological state of coma induced for religious or medical reasons? The importance of Jansen's article is that it established for the first time a point of convergence between various neurophysiological hypotheses of NDEs, even though a greater amount of data will be necessary to establish to what extent and in which way this model is effectively correlated with such experiences.

\section{References}

Carr, D. B. (1982). Pathophysiology of stress-induced limbic lobe dysfunction: A hypothesis for near-death experiences. Anabiosis: The Journal of Near-Death Studies, 2, 75-89.

Collier, B. B. (1972). Ketamine and the conscious mind. Anaesthesia, 27, 120-134.

Deecher, D. D., Teitler, M., Soderlund, D. M., Bornmann, W. G., Kuehne, M. E., and Glick, S. D. (1992). Mechanism of action of ibogaine and harmaline congeners based on radioligand binding studies. Brain Research, 571, 242-247.

Domino, E. F., Chodoff, P., and Corssen, G. (1965). Pharmacologic effects of CI-581, a new dissociative anesthetic, in man. Clinical and Pharmacological Therapeutics, 6, 279-285.

Fernandez, J. W. (1982). Bwiti: An ethnography of the religious imagination in Africa. Princeton, NJ: Princeton University Press.

Glick, S. D., Rossman, K, Dong, N., and Keller, R. W. (1993). Local effects of ibogaine on extracellular levels of dopamine and its metabolites in nucleus accumbens and striatum: Interactions with D-amphetamine. Brain Research, 628, 201-208.

Goutarel, R., Gollhofer, O., and Sillans, R. (1993). Pharmacodynamics and therapeutic applications of iboga and ibogaine. Psychedelic Monographs and Essays, 6, 71-111.

Grof, S. (1994). Books of the dead, manuals for living and dying. Singapore: Thames and Hudson.

Henry, W. D., and Mann, A. M. (1965). Diagnosis and treatment of delirium. Canadian Medical Association Journal, 93, 1156-1166.

Hurt, P. H., and Ritchie, E. C. (1994). A case of ketamine dependence. American Journal of Psychiatry, 151, 779.

Jansen, K. L. R. (1993). Non-medical use of ketamine. British Medical Journal, 306, 601-602.

Johnstone, R. E. (1973). A ketamine trip. Anesthesiology, 39, 460-461.

Lotsof, H. S., and Sisko, B. (1991). Endabuse (ibogaine HCl). Newsletter of the International Working Group on AIDS and Drug Use, 5, 40-43.

McCarthy, D. A., Chen, G., Kaump, D. H., and Ensor, C. (1965). General anesthetic and other pharmacological properties of 2-(O-chlorophenol)-2-methylaminocyclohexanone $\mathrm{HCl}$ (CI-581). Journal of New Drugs, 5, 21-31.

Moore, M., and Alltounian, H. (1978). Journeys into the bright world. San Francisco, CA: Para Research.

Parke-Davis and Co. (1969). Medical summary, ketalar, CI-581: A short-acting anesthetic. Ann Arbor, MI: Parke-Davis and Co.

Peters, L. G., and Prince-Williams, D. (1983). A phenomenological overview of trance. Transcultural Psychiatric Research Review, 20, 5-39.

Popik, P., Layer, R. T., and Skolnick, P. (1994). The putative anti-addictive drug ibogaine is a competitive inhibitor of $\left({ }^{3} \mathrm{H}\right) \mathrm{MK}-801$ binding to the NMDA receptor complex. Psychopharmacology, 114, 672-674. 
Popik, P., Layer, R. T., and Skolnick, P. (1995). 100 years of ibogaine: Neurochemical and pharmacological actions of a putative anti-addictive drug. Pharmacological Reviews, 47, 235-253.

Rogo, D. S. (1984). Ketamine and the near-death experience. Anabiosis: The Journal of Near-Death Studies, 4, 87-96.

Saavedra-Aguilar, J. C., and Gómez-Jeria, J. S. (1989). A neurobiological model for near-death experiences. Journal of Near-Death Studies, 7, 205-222.

Sedman, G. (1966). A phenomenological study of pseudohallucinations and related experiences. Acta Psychiatrica Scandinavica, 42, 35-70.

Sershen, H., Hashim, A., and Lajtha, A. (1994). Effect of ibogaine on serotoninergic and dopaminergic interactions in striatum from mice and rats. Neurochemical Reports, 19, 1463-1466.

Sheppard, S. G. (1994). A preliminary investigation of ibogaine: Case reports and recommendations for further study. Journal of Substance Abuse and Treatment, 11, 379-385.

Siegel, R. K., and Hirschman, A. (1984). Hashish near-death experiences. Anabiosis: The Journal of Near-Death Studies, 4, 70-86.

Swidersky, S. (1990). La religion bouiti. Histoire II (1848-1990) (L. G. Sbrocchi, Ed.). Ottawa, Canada: Legas. 